Portland State University

PDXScholar

\title{
An Assessment of the Factors Influencing the Selection of the Best Carsharing Alternative in Portland Area Using Hierarchical Decision Modeling (HDM)
}

\author{
Saeed Alzahrani \\ Portland State University \\ Ahmed Alzahrani \\ Portland State University \\ Xuran Dai \\ Portland State University \\ Wei-Chen Hsu \\ Portland State University \\ Follow this and additional works at: https://pdxscholar.library.pdx.edu/etm_fac \\ Rashi Tiwari

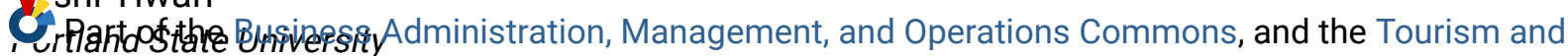 \\ Travel Commons

\section{Let us know how access to this document benefits you.}

\section{Citation Details}

Alzahrani, S., Alzahrani, A., Dai, X., Hsu, W. C., \& Tiwari, R. (2019, August). An Assessment of the Factors Influencing the Selection of the Best Carsharing Alternative in Portland Area Using Hierarchical Decision Modeling (HDM). In 2019 Portland International Conference on Management of Engineering and Technology (PICMET) (pp. 1-7). IEEE.

This Article is brought to you for free and open access. It has been accepted for inclusion in Engineering and Technology Management Faculty Publications and Presentations by an authorized administrator of PDXScholar. Please contact us if we can make this document more accessible: pdxscholar@pdx.edu. 


\title{
An Assessment of the Factors Influencing the Selection of the Best Carsharing Alternative in Portland Area Using Hierarchical Decision Modeling (HDM)
}

\author{
Saeed Alzahrani ${ }^{1,2}$, Ahmed Alzahrani ${ }^{1}$, Xuran Dai ${ }^{1}$, Wei-Chen Hsu ${ }^{1}$, Rashi Tiwari ${ }^{1}$ \\ ${ }^{1}$ Engineering and Technology Management Dept., Portland State University, Portland, USA \\ ${ }^{2}$ Management Information System Dept., King Saud University, Riyadh, Saudi Arabia
}

\begin{abstract}
Carsharing is a business model of car rentals that allows consumers to benefit from a private vehicle for short periods while being relieved of the costs of the purchase and maintenance. Carsharing is a growing industry and some players are trying to get a hold in the already competitive market. The current transportation market offers consumers many options for buying a vehicle, but fewer practical options for using a vehicle occasionally. Carsharing provides the benefits of allowing easy access to vehicles spread across the city that are rented per an hour or day. It is an increasingly common option for locals and tourists who want to get from one place to another without spending too much time on public transports. These have the added benefit of convenience and comfort of four-wheelers without paying much extra, as in the case of conventional rental cars, taxi, or cabs. This paper uses Hierarchical Decision Model (HDM) to evaluate the factors influencing the selection of the best carsharing alternative around Portland area by analyzing different perspectives and criteria that influence the selection. This paper address which criteria are most important to renters and provide recommendations for renters and carsharing businesses. The findings suggest that most essential criteria for the consumers are insurance coverage, reliability, rental cost, drop-off-options, and gas cost.
\end{abstract}

\section{INTRODUCTION}

Carsharing services are changing how people travel. Most rental car services provide a daily or monthly car for rent, making them impractical for short trips. In its most basic form, carsharing is rental car per hour or distance. The history of carsharing goes back to the period between the 1940s and 1980s in Europe [1]. Since then, it gained its popularity in the rest of the world. Carsharing has become a vital option for major metropolitan areas and urban cities, and has extended its existence to approximately 1,100 cities worldwide, in 26 nations on five continents with around 1.25 million carsharing members sharing 31,660 vehicles as of 2010 [2]. Carsharing members choose from a wide range of available cars listed at different rental prices and located in various locations. Most owned cars are estimated to sit idle over $90 \%$ of the day [3] [4]. Carsharing is considered a practical option for low-income households who find it difficult to spend a high amount of money on owning a vehicle that might occasionally be needed [5]. Economically, carsharing has lower fixed cost and higher variable cost [6] [5]. Carsharing provides a solution to the transportation issues of the major areas of the United States [7]. The excessive use of the vehicles results in increased traffic congestion, facility costs, and environmental impacts [5]. The U.S. resources used to provide parking spaces for cars, which are parked most of the day, are tremendous. Parking spaces use about 2,000 to 3,000 square miles of land and cost around $\$ 100$-billion of resource cost [8]. Carsharing is an innovative transportation method that has transformed how people travel.

The carsharing models include round-trip, one-way stationbased, free-floating and peer-to-peer carsharing [9]. Carsharing organizations operating in Portland have different business models and offerings for the consumer. In the Peer-to-Peer carsharing model, the member can choose from different cars offered by their owners who set the hourly or daily rates. In this model, members start the trip from the owner's listed location and end the trip at the same location. The second model is the one-way owned-fleet carsharing service model where members have few vehicle models scattered in a designated service area around Portland. In this model, the trip starts from the car location and ends by parking the car on the street anywhere within the company's service area. In this model, the company fixes hourly and daily rates. Another type of the owned-fleet carsharing service model is the round trip or station-based model where the trip starts from the carsharing company's assigned locations and ends at the starting point.

The growth of carsharing has changed the transportation landscape by providing a vehicle to people who need a vehicle occasionally, low-income household who cannot afford to buy a vehicle, reducing traffic congestion in the roads, reducing the costs to maintain a vehicle, and reducing the negative impacts on the environment. Carsharing benefits include providing a transportation option for people who only need a car occasionally and allowing the members to select from a wide array of cars depending on the need [5]. Carsharing provides economic and environmental benefits. It is deemed to help reduce the environmental pollution and cut down the transportation cost [3]. Carsharing services have dramatically affected private vehicle ownership. A study conducted in Germany concluded that carsharing services have contributed to the reduction in vehicle ownership by $7 \%-15 \%[10]$. In London, $37 \%$ of carsharing members indicated a change in their perceptions toward car ownership [11]. These perceptions include decisions to sell existing car or not to buy a car. In a 
study conducted about carsharing in San Francisco, 29\% of carsharing users had sold one or more of their cars [6]. It is estimated as well that each carsharing vehicles have removed 9 to 13 private vehicles from the roads in the U.S. and Canada [12]. It is found that carsharing members own fewer cars than non-members [13]. Carsharing is expected to reduce the vehicle miles traveled (VMT) by about $67 \%$ among carsharing users [6] [14]. A higher number of cars on the roads lead to higher road congestions and increased negative impacts on the environment which in return result in issues on the cities and citizens regarding social and economic well-being [15]. Carsharing helps reduce the number of cars on the roads since they are the primary source of urban air, noise and water pollution [5]. Each carsharing helps CO2-reduction per average carsharing user [16]. Carsharing adoption leads to decline in the greenhouse gas emissions [13]. Carsharing is proven to reduce transport-related energy use and greenhouse gas (GHG) emissions by $51 \%$ [17]. Moreover, the increasing number of cars on the roads increases the cost of their maintenance. Its estimated that $38 \%$ of the state of Wisconsin's local roads need immediate maintenance and repair which would result in savings of about $\$ 500$ million if the number of vehicles in roads decrease [18]. Carsharing models are built upon and has benefited from the technological advancements of the information and communication technology. Currently, in a click of a button, a car can be rented and returned. It is clear that carsharing has brought significant benefits from economic and environmental perspectives.

Several factors influence individual's decision to join the carsharing. Prospective members consider several factors in the decision to become carsharing members, which are cost, convenience, environmental reasons [14] [7], satisfactory with car ownership [14], occasional need for a car [7], time demand, and flexibility [19]. Other factors influencing the joining decision include higher costs of energy; limited and expensive parking in some areas [1]. Guaranteed parking provided by carsharing organizations in the crowded cities is also considered as motivation for joining carsharing [1]. Other motivations to join include traffic mitigation, transparency of costs and good value for money [19]. Individuals are becoming more aware of carsharing as a practical alternative mode of transportation and consider several factors that determine their willingness to join.

Portland and surrounding areas are a big travel location in the Northwest and attract thousands of tourists per year. Locals and Tourists especially these days prefer a four-wheeler at their disposal due to comfort and convenience. People often travel on a budget and carsharing provides them an option that is both economical and convenient. In 2016, the number of Portland visitors reached 9.1 million and generated around $\$ 5.2$ billion in direct spending which prove the need for carsharing service as another practical transportation mode [20]. The carsharing service enables visitors to visit attractions out of the trail area, like Mount Hood, Multnomah Falls, Oregon City, Woodburn county, etc. Portland city is considered as the first adopter of the carsharing concept in the U.S. [21] with the Car Sharing Portland (CSP) as the first commercial carsharing organization [7]. The Oregon Department of Environmental Quality published a report on the Car Sharing Portland (CSP) status in
Portland in 1997 [22]. The report showed that 26\% of CSP members sold their personal car and 53\% avoided a car purchase after joining CSP. From an economic perspective, the report showed that members could save up to $\$ 154$ per month on transportation costs as $75 \%$ of them became more aware of these costs. The Portland Office of Transportation conducted a one-year carsharing pilot program with Flexcar Portland, between 2004 and 2005, to evaluate the costs and benefits of supporting the carsharing concept in Portland city [21]. In the efforts to providing a feasible and practical transportation method to the existing once, the city of Portland assessed the benefits and issues of carsharing from different perspectives. These perspectives were public benefits for residents, environmental benefits, operational and enforcement issues related to public parking, and administrative issues rated to cost of service and fees [21]. On close analysis, we found out the list of five carsharing alternatives that are the biggest market players in Portland currently. There are five carsharing options available in Portland area which are Car2Go, Getaround, ReachNow, Turo, and Zipcar. These options have different business models and offerings to the consumer. Turo and Getaround are peer-to-peer carsharing services where the member can choose from different vehicles offered by their owners who set the hourly or daily rates. In this model, members start the trip from the owner's location and end the trip at the same location. Car2Go and Reachnow are company owned-fleet carsharing services where members have few vehicle models scattered in a designated service area around Portland. In this model, the trip starts from the car location and ends by parking the car on the street anywhere within the company's service area. In this model, the company fixes hourly and daily rates. Trips start from these assigned locations and end at the starting point. Zipcar hourly and daily rates vary by car model, size, and time.

\section{RESEARCH OBJECTIVE}

The research aim of this paper is to develop a hierarchical decision model (HDM) to evaluate the factors influencing the selection of the best carsharing alternative for locals and tourists around the Portland area by analyzing different perspectives and criteria, that can be used to:

- Address which criteria are most important to the users

- Provide recommendations to members and carsharing businesses.

\section{Methodology}

A hierarchical decision model (HDM) helps the decision maker by breaking down the decision problem into criteria and sub-criteria. This model is used to evaluate and assign a weighting to the perspectives and criteria. Thereby, bringing clarity to the diverse options available, and displaying the importance and utility of each option lucidly. HDM consists of stages that display the breakup of the decision problem [23]. In this paper, we used an HDM to structure the individual's selection decision into an objective, perspective, and criteria. The weights of each of these perspectives and criteria could be evaluated to determine their importance in the selection decision. For instance, a typical hierarchical decision model 
(HDM) are constructed as Fig. 1, which used to start from the establishment of the mission or aim, perspectives that are evaluated for their importance to the overall aim. Each perspective can break into different criterions. The level of the decision tree depends on the complexity of the problem. The connected line from the aim to each perspective means that the perspective must be compared pairwise for their importance concerning the aim. Likewise, the lines connecting each perspective to criteria express that criteria are compared pairwise as to which is more preferred for that perspective. A series of steps were undertaken to structure the selection decision [24]. They were: (1) Identify the perspectives and criteria that influence the user's decision to select the best carsharing alternative. (2) Build the pairwise comparisons survey and distribute it to the user's to capture their opinion. (3) Determine the weights of the perspectives and criteria by using the PCM software. (4) Evaluate and determine the relative importance of the perspectives and criteria to the overall objective of the decision to select the best carsharing alternative in Portland area. We also proposed suggestions for the carsharing users and businesses based on the assessment of the factors that influence the selection decision. The HDM has been used to evaluate alternatives and select best option as well as to evaluate the criteria that influence the selection [27].

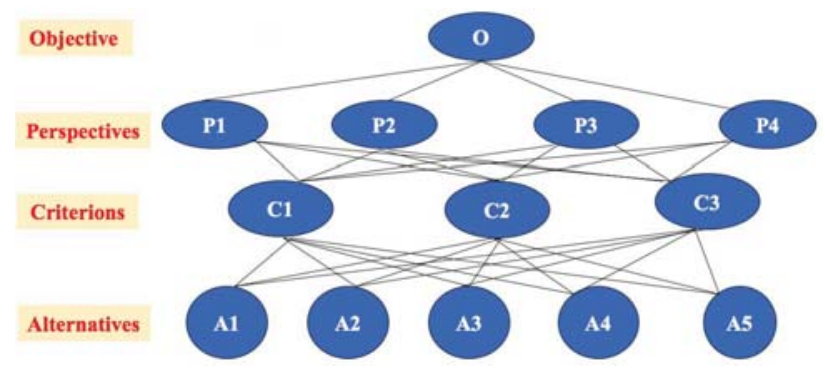

Fig. 1. A typical hierarchical decision model (HDM) [23]

\section{A. HDM Model Development}

The model for deciding on a carsharing service was developed with a tourist and locals in mind. What essential criteria do people look for while renting a car? What kind of requirements do people have while deciding on renting a car?

The paper starts by listing the perspectives that people base their decisions on when selecting a carsharing organization to join, like economic, convenience, etc. After that, it looked at the criteria of choosing a service based on these perspectives. For example, factors like mileage limit and car model, etc. were considered. The perspectives and criteria were extracted from the literature review and the expert panel. The perspectives and criteria are discussed in detail below. We then had experts evaluate and rank these criteria and perspectives based on their importance in the selection decision.

\section{B. Pairwise Comparison}

The pairwise comparison method will be used to determine the relative importance of each perspective and criteria to the overall decision. Relative scores will help us determine the weights of each criterion. These criteria when compared to each other in pairs, and the relative comparison will show us the successful order of the options. Pair-wise comparison combined with the HDM will guide us through choosing the ideal option while keeping in mind the selected criteria. Pairwise comparison software will be used to determine the weights of the perspectives and criteria and their relative importance to the objective [25].

\section{Objective $(O)$}

The primary aim of the project is to assess the factor influencing the selection of best carsharing option available around Portland area.

\section{Perspectives $(P)$}

Decision making is a complex task that involves various socio-economic and physical factors into account before evaluating options or making decisions. For this model, we have divided our approach into the following perspectives:

- Convenience: how comfortably the options are in terms of saving time, simplifying your work and making the task overall easy and requiring less difficulty. The convenience perspective includes criteria such as drop-off options, duration options, ease of access, fleet size, mileage limit, and parking availability.

- Economic: Relates to all types of costs and any other factor that can be valued in terms of monetary value such as gas cost, parking cost, miscellaneous cost, rental cost, and subscription cost.

- Features: Features provided in the vehicle and specialties that are customer preferences based on their area of travel, number and kind of people on board etc.. Features perspective include the type of car model, car size, and interior features.

- Safety: Matters that include but are not limited to general safety policies of the rental company, car owner. Policies followed for assistance in case of any mishap or broken vehicle, quality check of vehicles, etc.

\section{E. Criteria $(C)$}

We identified criteria for each perspective to provide better and accurate assessment of the factors influencing the selection decision. For our model, the criteria are as follows based on the perspectives described above:

\section{$>$ Convenience:}

- Drop-Off Options: These relate to where you can drop off the rented car and ranges from same pickup location to anywhere near your destination. It varies with company policies.

- Duration Options: The length of time for which you can keep the shared vehicle. It can range from few minutes to hours to daily rentals.

- Ease of Access: How easily can the car be accessed includes, but is not limited to, proximity to car pick up locations and rental process and faster reservations, etc. 
- Fleet Size: determines how readily the vehicles will be available for rental and larger car selection options.

- Mileage Limit: To avoid excessive wear and tear, carsharing companies keep a mileage limit. If you go over this limit there is an extra fee that you have to pay.

- Parking Availability: How easily can one get a parking space for the shared vehicle.

$>$ Economic:

- Gas Cost: If the cost of fuel, petrol, diesel, or gas is included or not in the rental.

- Parking Cost: Cost of parking the vehicle at designated parking places.

- Miscellaneous Cost: This includes but is not limited to extra mile cost, penalty fees, cancellation cost, and insurance upgrade cost

- Rental Cost: The hourly or daily cost of renting the shared vehicle. It depends on the duration of your renting.

- Subscription Cost: The cost to be eligible for renting cars from a particular carsharing company and can be one time, monthly, or annual payments.

\section{$>$ Features:}

- Car model: Model of the car being offered for rentals, can range from luxury to basic depending on the customer's needs.

- Car size: Size of the car being offered for rentals, focused on the number of the seats.

- Interior Features: we only considered if GPS was included or not.

$>$ Safety:

- Insurance coverage: Kind of insurance covers offered by the carsharing company and the deductible amount in case an accident happened.

- Reliability: How reliable is the company and its service and the quality of roadside assistance provided?

\section{F. Expert Panel}

Five experts made the development and evaluation of the model. The experts identified are at least members of one or more carsharing organizations in Portland and have used it at least once. The expert panel comes from four different countries and has used a carsharing as a tourist before locating in Portland and as locals. The perspectives and criteria were identified based on the experts' experience as consumers with the carsharing organizations they are subscribed with and from various research papers and websites that address such a problem. There are two steps: data collection and development of the ranking table. We came out with the four essential perspectives to determine the carsharing service from our literature review and expert's inputs, which are shown in the second level of our HDM model: economic, convenience, safety, and feature. Different criteria will evaluate each perspective.

\section{G. Assumptions:}

- The authors of this paper are the experts who completed the pairwise comparison survey.

- The experts are members of at least one or more carsharing organization and have rented at least one or more carsharing vehicle.

- The perspectives and criteria were identified with the tourists and locals in mind as well as the carsharing organizations operating in Portland.

- It is assumed that the carsharing vehicle will be used in conjunction with the public transports in Portland and to provide a more practical mode of transportation.

- The carsharing organizations kept in mind in this model are Zipcar, Turo, ReachNow, Car2go, and Getaround.

\section{RESUlt ANALysis AND DisCUSSION}

The HDM is used to structure the decision into objective, perspective, and criteria to better understand the critical factors to consumers when selecting the best carsharing alternative. The following sections show the result analysis and discussion:

\section{A. Perspectives Ranking}

The perspectives used in this model are Economic, Convenience, Safety, and Features. They were ranked using Pairwise Comparison Method (PCM) software provided by Portland State University to determine the relative importance of each perspective to the overall objective of the project. The following Table (1) shows experts weighting for perspectives regarding the objective. The mean for each perspectives' weightings for the experts was calculated:

\begin{tabular}{|c|c|c|c|c|c|}
\hline $\begin{array}{c}\text { Perspectives } \\
\text { Level }\end{array}$ & Convenience & Economic & Features & S afety & Inconsistency \\
\hline Expert 1 & 0.23 & 0.49 & 0.15 & 0.13 & 0.02 \\
\hline Expert 2 & 0.24 & 0.39 & 0.08 & 0.29 & 0.01 \\
\hline Expert 3 & 0.27 & 0.34 & 0.14 & 0.24 & 0 \\
\hline Expert 4 & 0.48 & 0.08 & 0.09 & 0.37 & 0.01 \\
\hline Expert 5 & 0.31 & 0.14 & 0.21 & 0.32 & 0.02 \\
\hline Mean & 0.306 & 0.288 & 0.134 & 0.27 & \\
\hline Disagreement & & & & & 0.033 \\
\hline
\end{tabular}

According to the above, the impact of perspective on the overall objective, the weight of convenience, economic, features and safety are $0.31,0.28,0.27$ and 0.13 , respectively. Convenience is the most critical perspective for renters when renting a carsharing vehicle, it is surprising that "Economic" is the second critical perspective, and Safety is just 0.01 lower than Economic. Nowadays, people are looking for the ease of use and convenience and not only focus on the cost. The quality of the trip matters and many people would like to pay a little bit more for convenience and to get a more comfortable car for the trip. 


\section{B. Inconsistency and Disagreement}

This model shows that level of inconsistency for all the expert's is below 0.10 which is in the acceptable range and can be said that the expert's judgments were consistent. Also, the disagreement level is 0.033 which is still less than 0.10 and within the acceptable range. The inconsistency level above 0.10 occurs when the choices of the preferences are not aligned. The experts answer to each pairwise comparison should be consistent and has an overall level of 0.10 and less for each expert. Inconsistency is considered as a measurement of validation for the results.

\section{Criteria Ranking}

For this model, 16 criteria that were believed to influence the selection of the best carsharing alternative were selected. The experts ranked each criterion concerning its corresponding perspective. The higher value that a criterion has, the higher its impact on its perspective. To identify the weighting for each criterion, a pairwise comparison was conducted. The following fig. (2) shows the weighting for each criterion to its perspective:

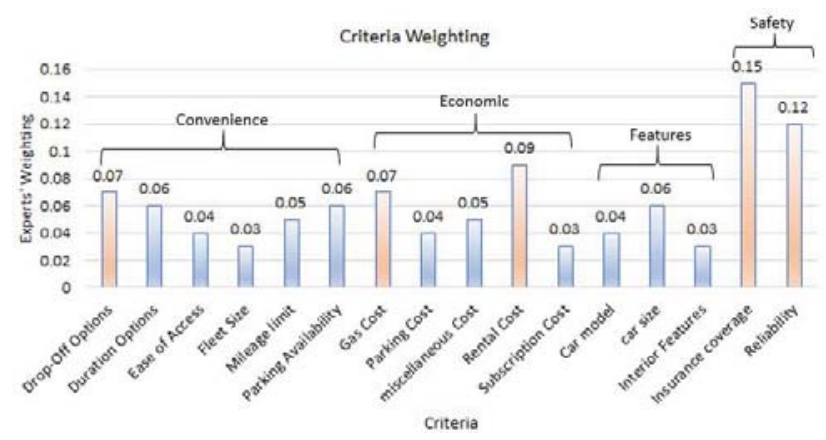

Fig. 2. Criteria weighting

The figure above shows each criterion relative importance to their perspective. In the perspective of convenience, drop-off options criterion has a score of 0.07 which is the most important criterion, followed by duration options and parking availability. The least essential criterion is fleet size. In the perspective of economic, the most critical criterion is rental cost and the least significant criteria is subscription cost. Rental cost always is the big part when considering carsharing, and depending on the carsharing company, some cost such as parking and gas are covered, and the subscription cost is low. In the perspective of safety, insurance coverage is the most important criteria, insurance may cost a lot when tourists have an accident, so it is understandable that people gave a higher rank on this. In the features perspective, users care more about the car size, and the least important is interior features. Tourists usually carry large luggage when traveling. For them it is vital that all the luggage can be put in one car, and nowadays many people use a mobile device as GPS, so whether the car has a GPS or not is not that important for them comparing to car size. The detailed ranking by each expert is shown in Appendix 1.

\section{Overall HDM Results}

The following fig. (3) shows the results of our HDM. The aim of this project is to find the factors influencing the selection of the best carsharing alternative for tourists and locals around the Portland area based on multi-criteria decision model. We utilized HDM to structure the decision into aim, perspectives, criteria, and alternatives. More details can be found in Appendix 1.

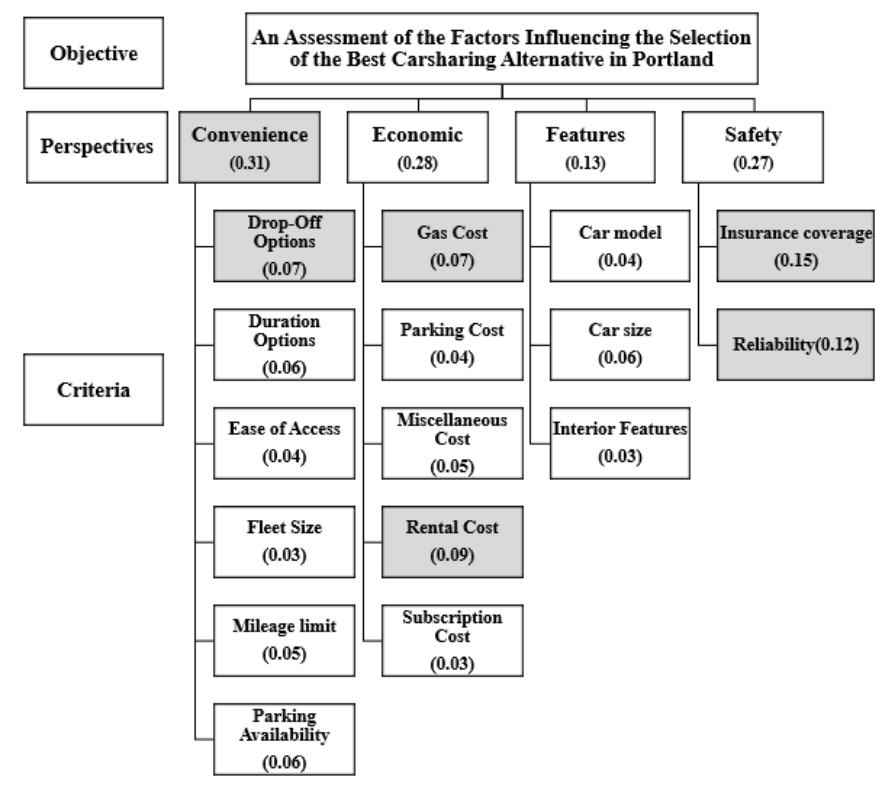

Fig. 3. The Final result of HDM

\section{E. Top Factors for Consumers}

After the evaluation of the criteria by the experts, we came up with the weights of the importance of each criterion under each perspective to the overall objective. The following table (2) shows the most important factors for consumers when selecting the best carsharing option.

\begin{tabular}{|c|c|c|}
\hline \multicolumn{2}{|c|}{ TABLE 2. IMPORTANT FACTORS FOR CONSUMERS } \\
\hline Top Important Factors & Perspective & Weight \\
\hline Insurance coverage & Safety & 0.15 \\
\hline Reliability & Safety & 0.12 \\
\hline Rental Cost & Economic & 0.09 \\
\hline Drop-Off Options & Convenience & 0.07 \\
\hline Gas Cost & Economic & 0.07 \\
\hline
\end{tabular}

The top factors should give insights to the carsharing companies about the criteria the consumers base their decision on when selecting a carsharing option.

\section{IMPLICATIONS}

\section{A. Recommendation}

In this project, a Hierarchical Decision Model (HDM) is used to identify the criteria that influence the selection of the best carsharing alternative for locals and tourists around Portland area. Our result shows that the convenience perspective is shown to be the most important in achieving the object and carsharing organizations should put more focus on 
improving areas related to convenience. The consumers appreciate the practicality aspect more than the feature or luxurious aspect. Table (2) above shows the most critical criteria to consumers that the carsharing organizations should pay close attention to in order to gain a competitive advantage over the other competitors and win the consumers' trust. It as well gives insights to the consumers who base their decision on specific criteria. For example, all carsharing organizations operating in Portland have insurance coverage included in the rate. So, it might be more competitive to provide full coverage or low deductible amount in case of an accident since the insurance coverage is ranked as the most important factor to the consumers. Moreover, if the consumers only care about the rental cost as one of the top factors, then GetAround outperforms the other carsharing options since the rate starts at $\$ 5$ per hour [26]. GetAround and Turo were ranked the lowest among other alternatives regarding Gas Cost since some other companies include the gas cost with the rental, so they need to put more effort in this area to satisfy the customers. However, the reason the gas cost is not included with the rental is that GetAround and Turo are peer-to-peer models where the renters rent the car from individuals living in their area while other operators are a company-owned fleet model. Drop-off options is another important factor to consumers as the Car2Go and ReachNow are outperforming others by allowing the car to be dropped off within a designated service area in the city where the other options require the car to be dropped off where it was picked up from. Overall, it seems that based on the topmost influencing factors of selection, the company-owned carsharing services are outperforming the other two peer-to-peer alternatives.

\section{B. Future Directions}

In this project, we have looked at the factors influencing the selection of best carsharing alternative in Portland area. However, the carsharing organizations operating in Portland might be added to the analysis to evaluate the best alternative for the consumer. Other companies may join the competition that can be evaluated with this model as well. Including the carsharing alternative and incorporating judgments from experts in the carsharing would enhance and validate the model either for the criteria selection or the pairwise comparison evaluation of the alternatives with regard to the criteria. Researchers and professionals in the carsharing area can add tremendous inputs in term of alternatives ranking.

\section{CONCLUSION}

In conclusion, the hierarchical decision model in conjunction with the pairwise comparison method gave us the most crucial factors consumers base their selection of the best carsharing alternative around Portland decision. This model can be used for other cities and a variety of consumers by altering the weights assigned to the perspectives and criteria as those were the expert's personal preference for this paper. Our research includes the perspectives and factors. However, adding alternatives in the evaluation would add significant value. The paper provides a better understanding of the factors matter to the consumers when selecting carsharing service and provides insights for the carsharing organizations to stay competitive and meet the consumers" needs. Based on our analysis and the weights assigned to the perspectives and criteria, we arrived at the conclusion that Insurance Coverage was the most critical criteria followed by Reliability and Rental Cost as the most important factors as shown in Table 3. It is worth mentioning that the experts had given convenience the maximum weighting while traveling in Portland city, followed by economical perspective.

\section{REFERENCES}

[1] S. Shaheen and A. Cohen, "Growth in Worldwide Carsharing: An International Comparison," Transportation Research Record: Journal of the Transportation Research Board, vol. 1992, pp. 81-89, Jan. 2007.

[2] S. A. Shaheen and A. P. Cohen, "Carsharing and Personal Vehicle Services: Worldwide Market Developments and Emerging Trends," International Journal of Sustainable Transportation, vol. 7, no. 1, pp. 534, Jan. 2013.

[3] R. C. Hampshire and S. Sinha, "A simulation study of Peer-to-Peer carsharing," in 2011 IEEE Forum on Integrated and Sustainable Transportation Systems, 2011, pp. 159-163.

[4] R. C. Hampshire and C. Gaites, "An Analysis of Person-to-Person Car Sharing," 2011, pp. 938-947.

[5] T. Litman, "Evaluating Carsharing Benefits," Transportation Research Record: Journal of the Transportation Research Board, vol. 1702, pp. 31-35, Jan. 2000.

[6] R. Cervero, A. Golub, and B. Nee, "City CarShare: Longer-Term Travel Demand and Car Ownership Impacts," Transportation Research Record: Journal of the Transportation Research Board, vol. 1992, pp. 70-80, Jan. 2007.

[7] R. Katzev, "Car Sharing: A New Approach to Urban Transportation Problems," Analyses of Social Issues and Public Policy, vol. 3, no. 1, pp. 65-86, Dec. 2003

[8] M. A. Delucchi, "THE ANNUALIZED SOCIAL COST OF MOTORVEHICLE USE IN THE U. S., 1990-1991: SUMMARY OF THEORY, DATA, METHODS, AND RESULTS.," University of California Transportation Center, 1998.

[9] M. Balac, F. Ciari, and K. W. Axhausen, "Carsharing Demand Estimation," Transportation Research Record: Journal of the Transportation Research Board, vol. 2536, pp. 10-18, Jan. 2015.

[10] F. Giesel and C. Nobis, "The Impact of Carsharing on Car Ownership in German Cities," Transportation Research Procedia, vol. 19, no. Supplement C, pp. 215-224, Jan. 2016.

[11] S. Le Vine and J. Polak, "The impact of free-floating carsharing on car ownership: Early-stage findings from London," Transport Policy, Feb. 2017.

[12] E. Martin, S. Shaheen, and J. Lidicker, "Impact of Carsharing on Household Vehicle Holdings: Results from North American Shared-Use Vehicle Survey," Transportation Research Record: Journal of the Transportation Research Board, vol. 2143, pp. 150-158, Dec. 2010.

[13] R. R. Clewlow, "Carsharing and sustainable travel behavior: Results from the San Francisco Bay Area," Transport Policy, vol. 51, no. Supplement C, pp. 158-164, Oct. 2016.

[14] T. Schuster, J. Byrne, J. Corbett, and Y. Schreuder, "Assessing the Potential Extent of Carsharing: A New Method and Its Implications," Transportation Research Record: Journal of the Transportation Research Board, vol. 1927, pp. 174-181, Jan. 2005.

[15] M. Glotz-Richter, "Car-Sharing - 'Car-on-call' for reclaiming street space," Procedia - Social and Behavioral Sciences, vol. 48, no. Supplement C, pp. 1454-1463, Jan. 2012.

[16] J. Firnkorn and M. Müller, "What will be the environmental effects of new free-floating car-sharing systems? The case of car2go in Ulm," Ecological Economics, vol. 70, no. 8, pp. 1519-1528, Jun. 2011.

[17] T. D. Chen and K. M. Kockelman, "Carsharing's life-cycle impacts on energy use and greenhouse gas emissions," Transportation Research Part D: Transport and Environment, vol. 47, no. Supplement C, pp. 276-284, Aug. 2016.

[18] "Wisconsin's Transportation Budget: Misplaced Priorities, Unmet Needs \& Better Alternatives." [Online]. Available: http://www.1kfriends.org/wp- 
content/uploads/2015/05/Alternative_Budget.pdf. [Accessed: 11-Jan2018].

[19] F. E. Prettenthaler and K. W. Steininger, "From ownership to service use lifestyle: the potential of car sharing," Ecological Economics, vol. 28, no. 3, pp. 443-453, Mar. 1999.

[20] "Visitor Statistics \& Research - Travel Portland." [Online]. Available: https://www.travelportland.com/about-us/visitor-statistics-research/. [Accessed: 11-Jan-2018].

[21] Portland Office of Transportation, "Evaluation of the City of Portland's Carsharing Pilot Program June 2004 - July 2005." [Online]. Available: https://www.portlandoregon.gov/shared/cfm/image.cfm?id=121293. [Accessed: 11-Jan-2018].

[22] R. Katzev, "CarSharing Portland: Review and Analysis of Its First Year," 1999.

[23] D. F. Kocaoglu, "A participative approach to program evaluation," IEEE Transactions on Engineering Management, vol. EM-30, no. 3, pp. 112 118, Aug. 1983.
[24] K. C. van Blommestein and T. U. Daim, "Residential energy efficient device adoption in South Africa," Sustainable Energy Technologies and Assessments, vol. 1, pp. 13-27, Mar. 2013.

[25] A. Shaygan, D. O. Gungor, H. Kutgun, and A. Daneshi, "Adoption Criteria Evaluation of Activity Tracking Wristbands for University Students," in 2017 Portland International Conference on Management of Engineering and Technology (PICMET), 2017, pp. 1-7.

[26] B. J. Bailey, A software Product for the Pair Wise Method of Judgment Quantification.

[27] "Car Sharing: Enterprise Carshare vs Zipcar vs car2go," Earth's Friends, 09-Jun-2015. [Online]. Available: https://www.earthsfriends.com/enterprise-carshare-vs-zipcar-vs-car2govs-turo-vs-getaround/. [Accessed: 16-Jan-2018].

\section{A. APPENDIX 1 - HDM RESUlt TABLE}

\begin{tabular}{|c|c|c|c|c|c|c|c|c|c|c|c|c|c|c|c|c|c|}
\hline & \multicolumn{6}{|c|}{ Convenience } & \multicolumn{5}{|c|}{ Economic } & \multicolumn{3}{|c|}{ Features } & \multicolumn{2}{|c|}{ Safety } & \multirow[b]{2}{*}{ Inconsistency } \\
\hline & $\begin{array}{l}\text { Drop-Off } \\
\text { Options }\end{array}$ & $\begin{array}{l}\text { Duration } \\
\text { Options }\end{array}$ & $\begin{array}{l}\text { Ease of } \\
\text { Access }\end{array}$ & $\begin{array}{l}\text { Fleet } \\
\text { Size }\end{array}$ & $\begin{array}{c}\text { Mileage } \\
\text { limit }\end{array}$ & $\begin{array}{c}\text { Parking } \\
\text { Availability }\end{array}$ & $\begin{array}{l}\text { Gas } \\
\text { Cost }\end{array}$ & $\begin{array}{l}\text { Parking } \\
\text { Cost }\end{array}$ & $\begin{array}{l}\text { Miscellaneous } \\
\text { Cost }\end{array}$ & $\begin{array}{c}\text { Rental } \\
\text { Cost }\end{array}$ & $\begin{array}{c}\text { Subscription } \\
\text { Cost }\end{array}$ & $\begin{array}{c}\text { Car } \\
\text { model }\end{array}$ & $\begin{array}{l}\text { Car } \\
\text { size }\end{array}$ & $\begin{array}{c}\text { Interior } \\
\text { Features }\end{array}$ & $\begin{array}{l}\text { Insurance } \\
\text { coverage }\end{array}$ & Reliability & \\
\hline Expert 1 & 0.04 & 0.06 & 0.03 & 0.03 & 0.05 & 0.02 & 0.09 & 0.06 & 0.12 & 0.18 & 0.04 & 0.04 & 0.09 & 0.02 & 0.07 & 0.06 & 0.02 \\
\hline Expert 2 & 0.03 & 0.05 & 0.05 & 0.03 & 0.05 & 0.03 & 0.13 & 0.06 & 0.06 & 0.1 & 0.04 & 0.02 & 0.04 & 0.02 & 0.19 & 0.1 & 0.01 \\
\hline Expert 3 & 0.09 & 0.06 & 0.03 & 0.02 & 0.04 & 0.03 & 0.08 & 0.07 & 0.04 & 0.1 & 0.05 & 0.06 & 0.05 & 0.03 & 0.17 & 0.07 & 0 \\
\hline Expert 4 & 0.11 & 0.09 & 0.05 & 0.04 & 0.03 & 0.16 & 0.02 & 0.01 & 0.01 & 0.03 & 0.01 & 0.06 & 0.02 & 0.01 & 0.13 & 0.24 & 0.01 \\
\hline Expert 5 & 0.06 & 0.04 & 0.05 & 0.03 & 0.08 & 0.05 & 0.02 & 0.02 & 0.04 & 0.05 & 0.01 & 0.04 & 0.09 & 0.08 & 0.21 & 0.11 & 0.02 \\
\hline Mean & 0.07 & 0.06 & 0.04 & 0.03 & 0.05 & 0.06 & 0.07 & 0.04 & 0.05 & 0.09 & 0.03 & 0.04 & 0.06 & 0.03 & 0.15 & 0.12 & \\
\hline Minimum & 0.03 & 0.04 & 0.03 & 0.02 & 0.03 & 0.02 & 0.02 & 0.01 & 0.01 & 0.03 & 0.01 & 0.02 & 0.02 & 0.01 & 0.07 & 0.06 & \\
\hline Maximum & 0.11 & 0.09 & 0.05 & 0.04 & 0.08 & 0.16 & 0.13 & 0.07 & 0.12 & 0.18 & 0.05 & 0.06 & 0.09 & 0.08 & 0.21 & 0.24 & \\
\hline Std. Deviation & 0.03 & 0.02 & 0.01 & 0.01 & 0.02 & 0.05 & 0.04 & 0.02 & 0.04 & 0.05 & 0.02 & 0.01 & 0.03 & 0.02 & 0.05 & 0.06 & \\
\hline Disagreement & & & & & & & & & & & & & & & & & 0.033 \\
\hline
\end{tabular}

